\title{
Inverse Segregation in Unidirectionally Solidified Al-Cu Alloy Ingots*
}

\author{
By Tetsuichi Motegi** and Atsumi Ohno**
}

\begin{abstract}
Several experiments were carried out to study the formation mechanism of inverse segregation in $\mathrm{Al}-\mathrm{Cu}$ alloy ingots.

Al-4 mass \% Cu alloy ingots solidified horizontally in a stainless steel mold showed only a columnar zone and inverse segregation. However, an Al-14 mass $\% \mathrm{Cu}$ alloy exhibited either only equiaxed crystals or a columnar-equiaxed transition structure depending on the cooling temperature. No clear inverse segregation occurred in these ingots. It is considered that equiaxed crystals moved with the flow of the melt, and these crystals were irregularly distributed when it solidified.

All ingots solidified from the bottom or from the molten surface in a stainless steel mold or a graphite mold showed inverse segregation. In particular, an equiaxed zone in the Al-14 mass $\% \mathrm{Cu}$ alloy solidified from the molten surface in the graphite mold had an extremely low Cu concentration.

On a chill face of ingots decanted during the unidirectional solidification, the $\mathrm{Cu}$ concentration was always higher than the mean concentration of the alloy. This suggests that the solute $\mathrm{Cu}$ was already concentrated near the chill face at the initial stage of solidification. It is considered that the solute was trapped among the crystals of the stable solid shell formed on the mold wall.
\end{abstract}

(Received August 22, 1983)

Keyzords: inverse segregation, macrosegregation, unidirectional solidification, decantation, aluminum-copper alloy

\section{Introduction}

Inverse segregation in ingots and castings has been known for a long time as a phenomenon in which the solute content of the surface layer becomes higher than that of the center region. Typical examples of inverse segregation are the copper-rich surface layer in a duralumin ingot and the tin sweat of a bronze casting.

Various formation mechanisms for such segregation have been proposed and, in most of the studies on this, segregation has been thought to occur because the solute-rich melt that ought to finally solidify flows back towards the solidified surface layer due to some driving force. However, different interpretations have been given by studies about the driving force that causes the back flow.

Obinata $^{(1)}$ has summarized these interpretations in a report of studies prior to 1940 . His report lists the following forces which could be responsible for the back flow.

* This paper was originally published in Japanese in J. Japan Inst. Metals, 46 (1982), 323.

** Department of Metallurgical Engineering, Chiba Institute of Technology, Narashino 275, Japan.
(1) Pressure from growing crystals;

(2) Vapor pressure;

(3) Pressure due to contraction;

(4) Gas pressure;

(5) Volume contraction of crystals etc. Among these theories, Obinata ${ }^{(1)}$ supported theory (5) in accordance with his own experiments. He explained that the volume contraction of crystals produced small gaps among crystals and the remaining liquid was sucked into the gaps by the capillary action.

Later, Nakatani( ${ }^{(2)}$ also compiled a study concerning the formation mechanism of inverse segregation, which showed that inverse segregation was attributable to the back flow of solute-rich melt caused by the contraction on solidification.

In contrast to the back flow theories described above, Massing ${ }^{(3)}$ and Muromachi(4) showed that undercooling occurred in the melt near the mold wall at the start of the solidification and this caused non-equilibrium solidification resulting in the solute-rich layer. Furthermore, Muromachi ${ }^{(4)}$ showed that a second solute-rich layer was formed in the internal region of an ingot and explained that this region was formed by the back flow of solute- 
rich melt into dendrites. Jehmlich ${ }^{(5)}$ observed directly the solidification process by X-rays and found that the solute had already become concentrated near the mold wall at the early stages of solidification and inverse segregation occurred for this reason.

However, studies ${ }^{(6)-(12)}$ published recently have again adopted the previous theory that solute-rich melt flows back towards the surface layer of an ingot due to the contraction of the dendritic solidification. There have also been attempts to quantitatively analyse the degree of concentration of solute in the surface layer of an ingot using a numerical formula ${ }^{(10)-(12)}$.

In a study which explains inverse segregation as being based on the back flow of solute-rich melt, the features of the phenomenon are commonly described as follows:

(1) Alloys have the dendritic solidification morphology.

(2) Solidification proceeds successively towards the thermal center.

(3) Contraction occurs, as solidification takes place.

On the other hand, some papers ${ }^{(13)-(15)}$ show that inverse segregation occurs also in alloy ingots which have no dendritic solidification morphology, or in those which expand on solidification, or even in ingots consisting only of an equiaxed crystal structure. Accordingly, it seems that the back flow of the interdendritic liquid is not the whole cause of inverse segregation; hence it is necessary to consider some other formation mechanisms.

The authors ${ }^{(16)}$ have previously carried out studies on the relationship between the formation mechanism of the solidified structures and the macrosegregation of an ingot by directly observing the process of horizontally unidirectional solidification of $\mathrm{Sn}-\mathrm{Bi}$ and $\mathrm{Bi}-\mathrm{Sn}$ alloys. In that study it was found that the primary crystals of these alloys moved in the melt and gathered to form an equiaxed zone or an angular free crystal zone and the solute content of these zones of the alloy became lower than the mean solute content of the alloy, so that macrosegregation might also be caused by the movement of crystals in the melt.

Gullman and Johansson ${ }^{(17)}$ also found the phenomena of crystal separation and move- ment by observing directly the process of solidification of $\mathrm{Cu}-\mathrm{Sn}, \mathrm{Cu}-\mathrm{Si}, \mathrm{Cu}-\mathrm{P}, \mathrm{Cu}-\mathrm{Ni}$ and $\mathrm{Cu}-\mathrm{O}$ alloys. From these results, it is considered that the crystal separation theory suggested by the authors ${ }^{(18)}$ can be applied to the equiaxed crystals formed in the ingots of many solid solution alloys.

Based on the crystal separation theory, the present study was carried out for the purpose of obtaining basic data to clarify the formation mechanism of inverse segregation which occurs in $\mathrm{Al}-\mathrm{Cu}$ alloy ingots.

Firstly, experiments on horizontal and vertical unidirectional solidification were carried out, and the relationship between the distribution of copper and the macrostructure of the ingots was examined. Next, decantation was carried out at the specified times while unidirectional solidification was proceeding, to find out whether the solute concentration in the surface layer of an ingot already occurred during the stage in which the solid shell formed at the beginning of solidification or whether it was formed by the back flow of interdendritic liquid.

\section{Experimental Procedure}

Materials for making the samples were 99.99 mass $\% \mathrm{Al}$ and $\mathrm{Al}-33$ mass $\% \mathrm{Cu}$ master alloy. By melting them in graphite crucibles under atmospheric pressure, Al-4 mass $\% \mathrm{Cu}$ and $\mathrm{Al}-14$ mass $\% \mathrm{Cu}$ alloys were made.

\section{Experiments for horizontally unidirectional solidification}

Figure 1 shows a schematic representation of the experimental apparatus consisting of a horizontal-type electric furnace with nichrome heater, a stainless steel mold and a box for water cooling. The dimensions of the mold were $102 \mathrm{~mm} \times 30 \mathrm{~mm}$ in base area, $5 \mathrm{~mm}$ in height and $1.2 \mathrm{~mm}$ in wall thickness. Alumina mold wash was applied thinly to the inner surface of the mold except for the water cooling part. C.A thermocouples were set at two positions. One position was $5 \mathrm{~mm}$ from the cooling end of the molten metal and the other was where solidification was completed. After preheating this mold to $1073 \mathrm{~K}$ in the furnace shown in 


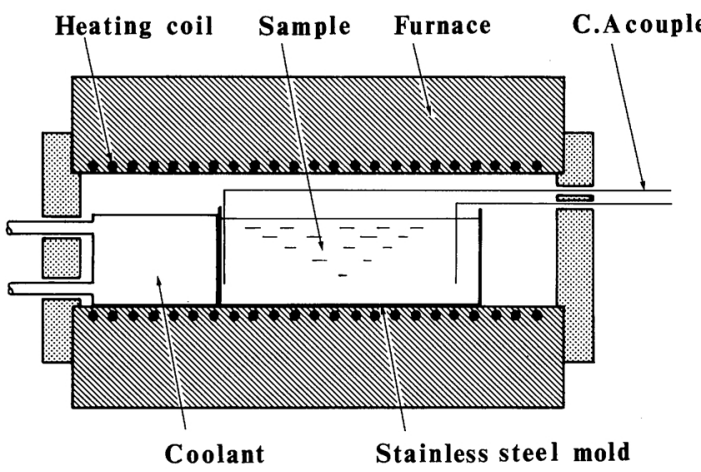

Fig. 1 Schematic representation of the experimental apparatus for the horizontal unidirectional solidification.

Fig. 1, a sample was poured into the mold at $1073 \mathrm{~K}$. The sample was furnace-cooled, until the cooling end reached a desired temperature, and then water was immediately passed through the cooling box provided at one end of the mold to cause unidirectional solidification. The starting temperature of water cooling was $933 \mathrm{~K}$ or $1033 \mathrm{~K}$.

Based on a report ${ }^{(19)}$ concluding that the depth of molten metal affected the degree of convection and ingot structure, values of three depths, $15 \mathrm{~mm}, 30 \mathrm{~mm}$ and $40 \mathrm{~mm}$, were used. The weight of the sample per charge was $0.14 \mathrm{~kg}, 0.27 \mathrm{~kg}$ and $0.41 \mathrm{~kg}$ corresponding to the three depths, respectively.

\section{Experiments for vertically unidirectional solidification}

Figure 2 shows a schematic representation of the experimental apparatus consisting of a vertical-type electric furnace, a stainless steel mold and a water cooled device. The mold was cylindrical with dimensions of $35 \mathrm{~mm}$ O.D. $\times$ $25 \mathrm{~mm}$ I.D. $\times 120 \mathrm{~mm}$ depth, and graphite mold wash applied thinly to the inside of the mold. The hot junctions of four thermocouples were set in the mold wall at a depth of $1 \mathrm{~mm}$ from its inner surface and spaced at equal intervals of $32 \mathrm{~mm}$ from the bottom to the top of the mold to record temperatures during the unidirectional solidification. The mold was preheated to $1073 \mathrm{~K}$ and then a sample of $0.15 \mathrm{~kg}$ of melt, heated up to $1073 \mathrm{~K}$, was poured into the mold. Unidirectional solidification was achieved by water cooling the mold bottom or by placing a

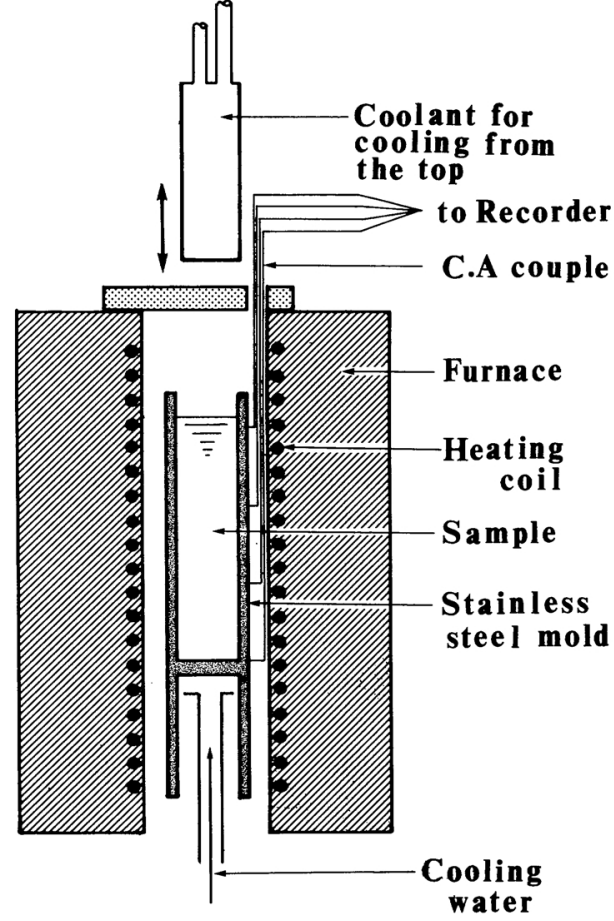

Fig. 2 Schematic representation of the experimental apparatus for the vertical unidirectional solidification.

water cooled block in contact with the molten surface immediately after furnace-cooling the sample to a desired temperature. The temperature at which water cooling began was $933 \mathrm{~K}$ or $1033 \mathrm{~K}$, and in each case, the mold temperature nearest the cooling end was taken as a reference.

Unidirectional solidification experiments were conducted from the bottom or the top in the same way as for the stainless steel mold to compare macrostructure and inverse segregation with different mold materials. This was done using a graphite mold with the same dimensions as the stainless steel mold, and by placing it on the water cooling table or with the water cooling block in contact with the molten surface.

\section{Experiments to observe the segregation layer in the early stages of solidification using the decantation method}

Decantation during unidirectional solidification was carried out using the experimental apparatus shown in Fig. 2. Decantation during unidirectional solidification starting from the 
bottom was performed by inverting the mold together with the furnace equipped with trunnions at a specified time after the start of the water cooling. To perform decantation during cooling from the molten surface, the mold bottom to which a steel wire was connected was fixed to the mold body using alumina cement. It was removed by pulling the wire downwards quickly to discharge the remaining liquid. Decantation was done at $10 \mathrm{~s}, 25 \mathrm{~s}, 60 \mathrm{~s}$ or $120 \mathrm{~s}$ after the start of water cooling at $933 \mathrm{~K}$, and ingots of various heights were obtained.

\section{Observation of macrostructure and determination of copper concentration in ingots}

Each ingot obtained by the above experiments was cut vertically into two equal parts, polished and etched to examine its macrostructure. An emission spectroscopic analyser was used to determine the copper content at various ingot positions. The points at which analysis was carried out were on the face perpendicular to the direction of growth which was from either the water cooled end or the part where solidification was completed. In other parts of the ingot, analysis points were spaced at $10 \mathrm{~mm}$ intervals along the growth direction on the faces of the equally divided parts of ingot. On the horizontally unidirectionally solidified ingots, the one with a height of $30 \mathrm{~mm}$ was analysed at two points, $10 \mathrm{~mm}$ and $20 \mathrm{~mm}$, from the bottom at $10 \mathrm{~mm}$ intervals from the water cooling end. The one with a height of $40 \mathrm{~mm}$ was analysed at three points, $7 \mathrm{~mm}$, $20 \mathrm{~mm}$ and $33 \mathrm{~mm}$ from the bottom and at $10 \mathrm{~mm}$ intervals from the water cooling end. The mean value on the measurement of the two points or three points was taken as the value at the corresponding distance from the cooling end.

\section{Results}

1. The relationship between the macrostructure and distribution of copper content in horizontally unidirectionally solidified ingots

Figure 3(a) and (b) show the typical macro- structure of ingots of $\mathrm{Al}-4 \% \mathrm{Cu}$ alloy, in which the depth of molten metal is $40 \mathrm{~mm}$, and the ingots were unidirectionally solidified by water cooling at its left end at either $933 \mathrm{~K}$ or $1033 \mathrm{~K}$. In both cases, only a columnar structure developed from the cooling end was obtained. The mean solidification rate of the ingot in Fig. 3(a) was $1.3 \mathrm{~mm} / \mathrm{s}$ and that in Fig. 3(b) was $1.1 \mathrm{~mm} / \mathrm{s}$.

Figure 4 shows the copper concentration of these ingots at various positions, and in both cases, the copper concentration was higher at
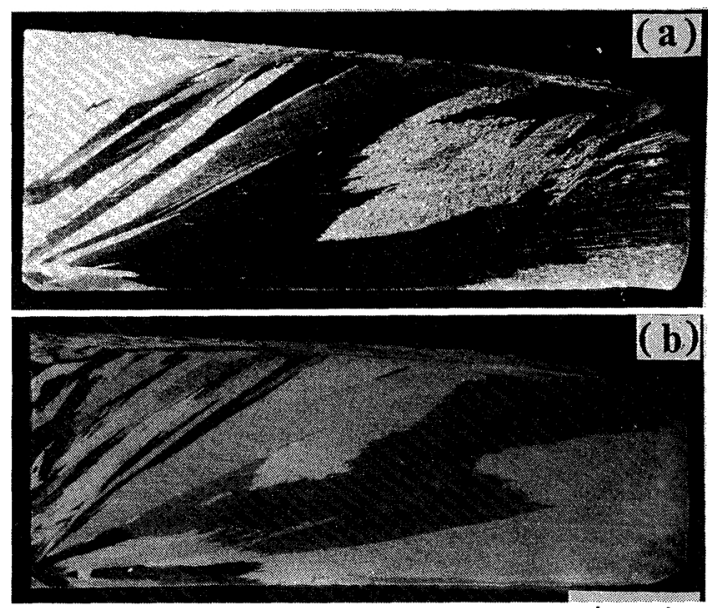

$1 0 \longdiv { \mathrm { mm } }$

Fig. 3 Macrostructures of $\mathrm{Al}-4 \% \mathrm{Cu}$ alloy ingot solidified from the left to the right; (a) water cooled at $933 \mathrm{~K}$, (b) water cooled at $1033 \mathrm{~K}$.

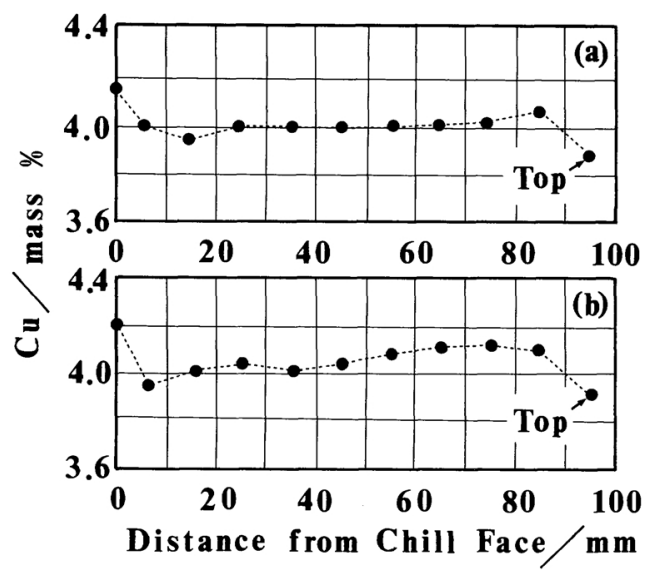

Fig. 4 Variation of $\mathrm{Cu}$ concentration along the length of $\mathrm{Al}-4 \% \mathrm{Cu}$ alloy ingots solidified from the left to the right; (a) water cooled at $933 \mathrm{~K}$, (b) water cooled at $1033 \mathrm{~K}$. 
the cooling end than the mean concentration and lower at the end where solidification was completed. However, the copper concentration at the analysis points in the central part between both ends increased gradually, as the distance from the cooling end increased. Similar tendencies were observed where the depth of molten metal was $15 \mathrm{~mm}$ and $30 \mathrm{~mm}$; thus, the effect of the depth of the molten metal on the macrostructure and the distribution of copper concentration could not be determined. Figure 5(a) shows the structure of an $\mathrm{Al}-14 \% \mathrm{Cu}$ alloy
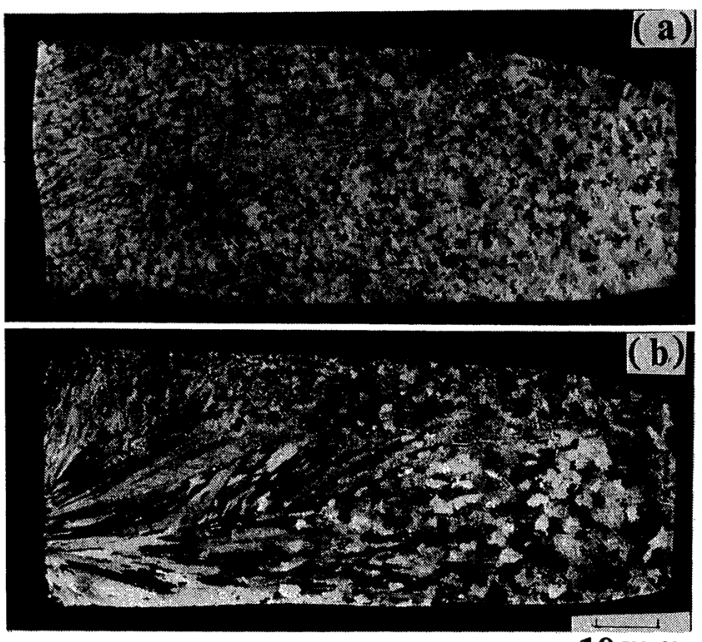

$10 \mathrm{~mm}$

Fig. 5 Macrostructures of $\mathrm{Al}-14 \% \mathrm{Cu}$ alloy ingot solidified from the left to the right; (a) water cooled at $933 \mathrm{~K}$, (b) water cooled at $1033 \mathrm{~K}$.

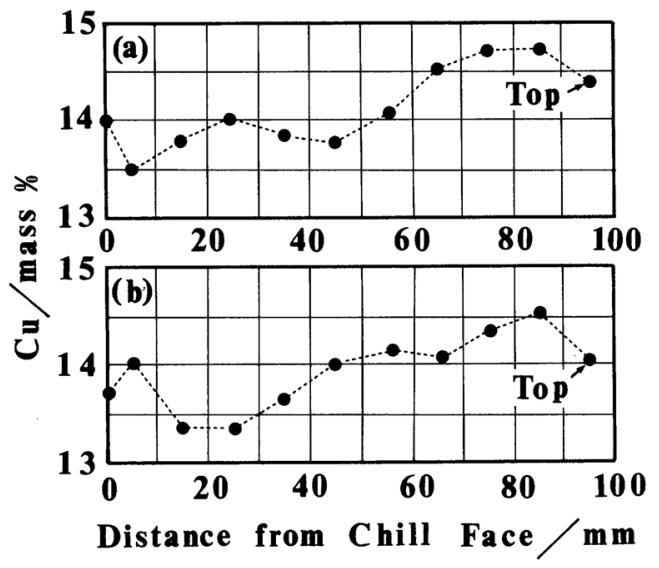

Fig. 6 Variation of $\mathrm{Cu}$ concentration along the length of $\mathrm{Al}-14 \% \mathrm{Cu}$ alloy ingots solidified from the left to the right; (a) water cooled at $933 \mathrm{~K}$, (b) water cooled at $1033 \mathrm{~K}$. ingot where water cooling was started at $933 \mathrm{~K}$, and the ingot was formed of equiaxed crystals throughout. Figure 5(b) shows the ingot in which water cooling was started at $1033 \mathrm{~K}$, and here are observed columnar crystals grown from the cooling end and equiaxed crystals in front of the columnar crystals and in the upper part of the ingot. The mean solidification rate of ingot in Fig. $5(\mathrm{a})$ was $1.9 \mathrm{~mm} / \mathrm{s}$ and that in Fig. 5(b) was $1.1 \mathrm{~mm} / \mathrm{s}$.

Figure 6 shows the distribution of copper concentration for $\mathrm{Al}-14 \% \mathrm{Cu}$ alloy ingots at various positions. It is apparent that no inverse segregation was observed in either of them.

The influence of the depth of molten metal on the solidified structure was not revealed in the $\mathrm{Al}-14 \% \mathrm{Cu}$ alloy either. It was found that a major factor influencing the ingot structure was the starting temperature of the water cooling rather than the depth of molten metal.

2. Relationship between the macrostructure and the distribution of copper concentrations in ingots unidirectionally solidified from the mold bottom or the molten surface

Figure 7 shows the macrostructure of ingots

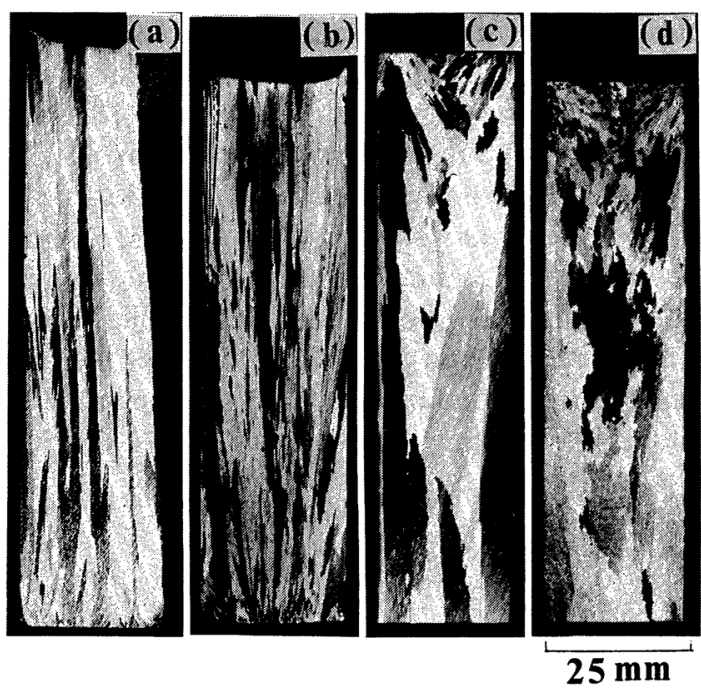

Fig. 7 Macrostructures of $\mathrm{Al}-\mathrm{Cu}$ alloy ingots water cooled at $933 \mathrm{~K}$ in the stainless steel mold; (a), (b) solidified from the bottom, (c), (d) solidified from the molten surface, (a), (c) $\mathrm{Al}-4 \% \mathrm{Cu}$, (b), (d) Al-14\% Cu. 
of $\mathrm{Al}-4 \% \mathrm{Cu}$ and $\mathrm{Al}-14 \% \mathrm{Cu}$ alloys water cooled from the bottom and the molten surface. They show only columnar crystals, regardless of the starting temperature of the water cooling. Figures 8 and 9 show typical examples of the cooling curves of various positions in the melt when water cooled from the mold bottom and the molten surface. From these results, it was found that solidification proceeded successively from the cooling end.

Figure 10 shows the distribution of copper concentration in the ingot shown in Fig. 7. It was found that the copper concentration at the cooling end was always higher than the mean concentration of the alloy either at the mold bottom or on the top surface, and at the place where solidification was completed, the copper concentration was always lower than the mean value. A similar macrostructure and distribution of copper concentration was obtained in the ingots which were water cooled from $1033 \mathrm{~K}$.

On the other hand, an entirely columnar structure was obtained in both $\mathrm{Al}-4 \% \mathrm{Cu}$ and
A1-14\% $\mathrm{Cu}$ alloy ingots regardless of the starting temperature of the water cooling, when a graphite mold water cooled from the bottom was used. However, when the molten metal was cooled from the top surface, only a columnar structure was observed in the case of the Al$4 \% \mathrm{Cu}$ alloy, while in the case of the $\mathrm{Al}-14 \% \mathrm{Cu}$, an equiaxed zone appeared at the bottom of the ingot. Figure 11 shows typical macrostructures of these ingots water cooled at $933 \mathrm{~K}$. Similar behavior was found, when water cooling was started at $1033 \mathrm{~K}$.

Figure 12 shows the distribution of copper concentration in the $\mathrm{Al}-14 \% \mathrm{Cu}$ alloy water cooled from the molten surface. The copper concentration near the cooling end was higher than the mean copper concentration of the alloy, but at the bottom, the copper concentration of an ingot in which an equiaxed zone was present was much lower than that of an ingot consisting of only columnar crystals.

\section{Segregation layer near the cooling end}

With the examples of the application of

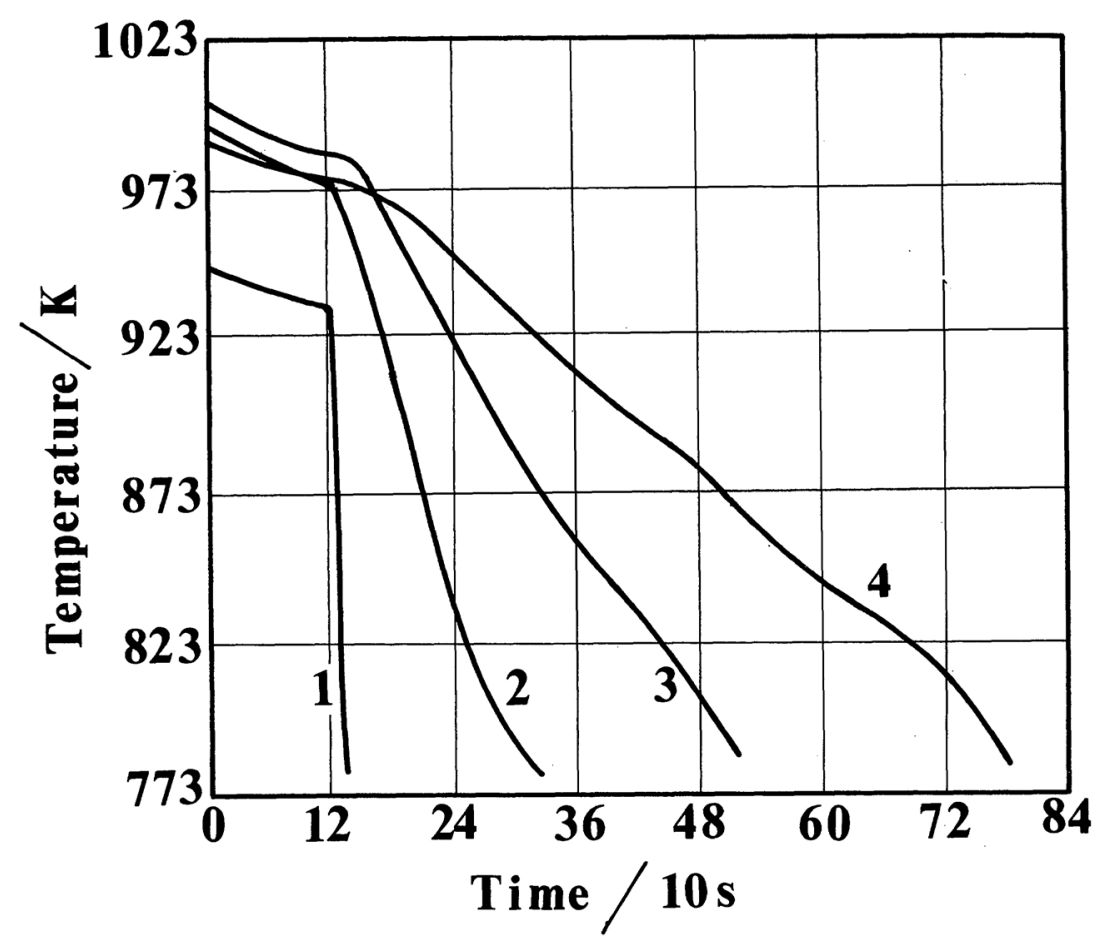

Fig. 8 Cooling curves of $\mathrm{Al}-14 \% \mathrm{Cu}$ alloy ingot during unidirectional solidification from the bottom. Cooling curves No. 1, No. 2, No. 3 and No. 4 were obtained at 0, 32, 64 and $96 \mathrm{~mm}$ from the bottom, respectively. 


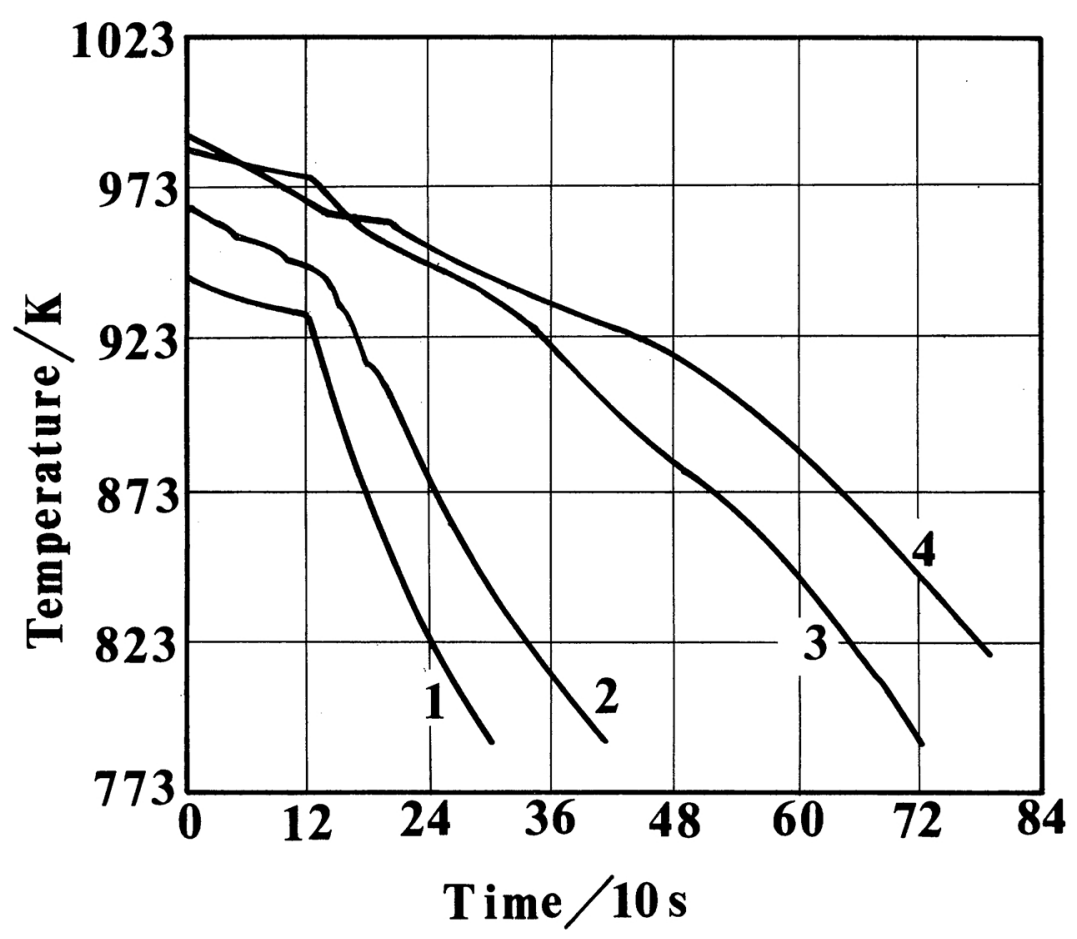

Fig. 9 Cooling curves of $\mathrm{Al}-4 \% \mathrm{Cu}$ alloy ingot during unidirectional solidification from the molten surface. Cooling curves No. 1, No. 2, No. 3 and No. 4 were obtained at 0, 32, 64 and $96 \mathrm{~mm}$ from the molten surface, respectively.

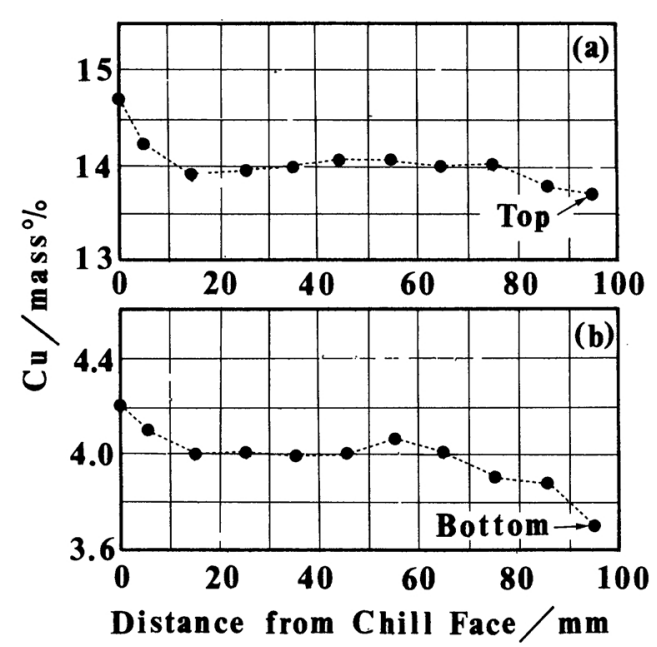

Fig. 10 Variation of $\mathrm{Cu}$ concentration along the length of $\mathrm{Al}-\mathrm{Cu}$ alloy ingots solidified in the vertical direction in the stainless steel mold; (a) $\mathrm{Al}-14 \% \mathrm{Cu}$ alloy water cooled at $933 \mathrm{~K}$ from the bottom, (b) $\mathrm{Al}-4 \% \mathrm{Cu}$ alloy water cooled at $933 \mathrm{~K}$ from the molten surface. decantation at specified times during unidirecti onal solidification from the mold bottom or the molten surface, where the $\mathrm{Al}-4 \% \mathrm{Cu}$ alloy is cooled from the bottom, the thickness of the solid shell was $7.6 \mathrm{~mm}$ when carrying out decantation after $10 \mathrm{~s}, 18.1 \mathrm{~mm}$ after $25 \mathrm{~s}$, $39 \mathrm{~mm}$ after $60 \mathrm{~s}$, and $58 \mathrm{~mm}$ after $120 \mathrm{~s}$, respectively. When cooled from the molten surface, the thickness was $7.8 \mathrm{~mm}$ after $10 \mathrm{~s}, 19 \mathrm{~mm}$ after $25 \mathrm{~s}, 36 \mathrm{~mm}$ after $60 \mathrm{~s}$, and $56 \mathrm{~mm}$ after $120 \mathrm{~s}$, respectively. The macrostructures of these ingots were all entirely composed of columnar crystals.

Figures 13 and 14 show the copper concentration of a solid shell obtained as a result of carrying out decantation at specified times. From these results, it was found that the copper concentration of the solid shell was higher than the mean concentration of the alloy regardless of the cooling direction and the alloy composition even from the early stage of solidification when the solid shell was very thin, and the copper concentration of solid shell did not neces- 

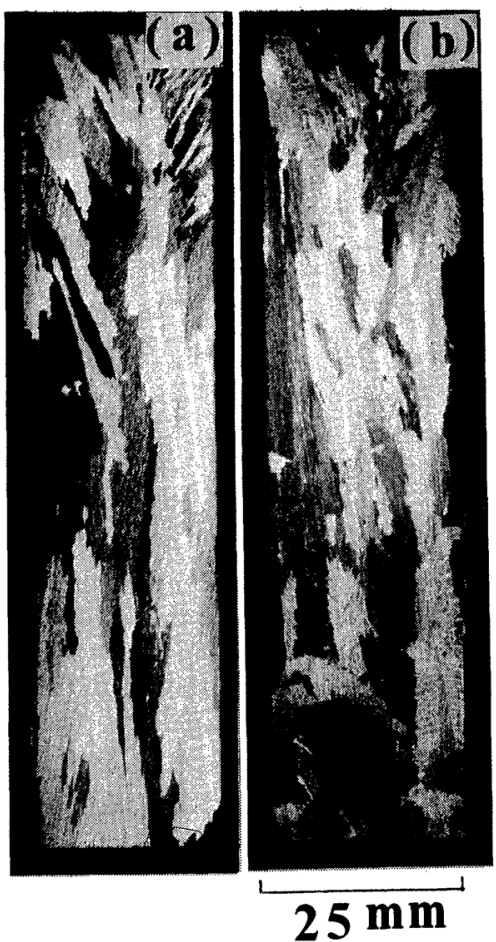

Fig. 11 Macrostructures of $\mathrm{Al}-\mathrm{Cu}$ alloy ingots water cooled at $933 \mathrm{~K}$ from the molten surface in the graphite mold; (a) $\mathrm{Al}-4 \% \mathrm{Cu}$, (b) $\mathrm{Al}-14 \% \mathrm{Cu}$.

sarily increase with the passage of time.

\section{Consideration}

\section{Inverse segregation in ingots with columnar structure}

It was found that in an ingot consisting entirely of columnar crystals, the copper concentration was higher than the mean copper concentration of the alloy at the cooling end and in a region up to about $5 \mathrm{~mm}$ thick from the cooling end, while at the end where solidification was completed, the copper concentration was lower than the mean concentration. To clarify the cause of the formation of the copperrich layer near the cooling end, decantation was carried out at specified times during the unidirectional solidification. As a result, it was found that the copper concentration near the cooling end was already higher than the mean concentration when the solid shell was formed at the beginning of solidification. In addition,

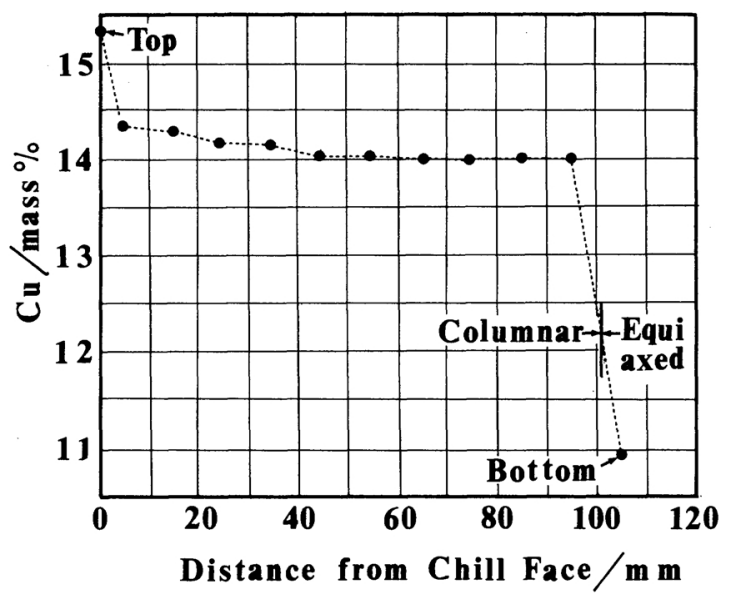

Fig. 12 Variation of $\mathrm{Cu}$ concentration along the length of $\mathrm{Al}-14 \% \mathrm{Cu}$ alloy ingot water cooled at $933 \mathrm{~K}$ from the molten surface in the graphite mold.

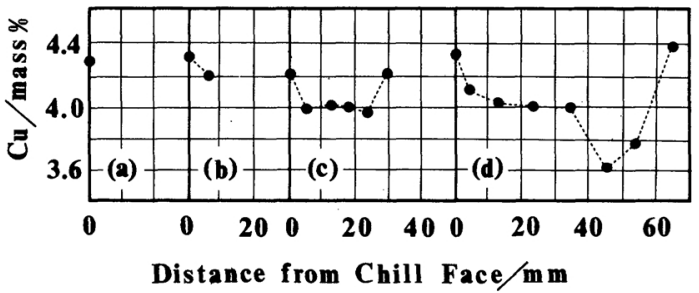

Fig. 13 Variation of $\mathrm{Cu}$ concentration along the length of $\mathrm{Al}-4 \% \mathrm{Cu}$ alloy ingot decanted at the specified times during the unidirectional solidification from the bottom; (a) $10 \mathrm{~s}$, (b) $25 \mathrm{~s}$, (c) $60 \mathrm{~s}$, (d) $120 \mathrm{~s}$ after start of the water cooling at $933 \mathrm{~K}$, respectively.

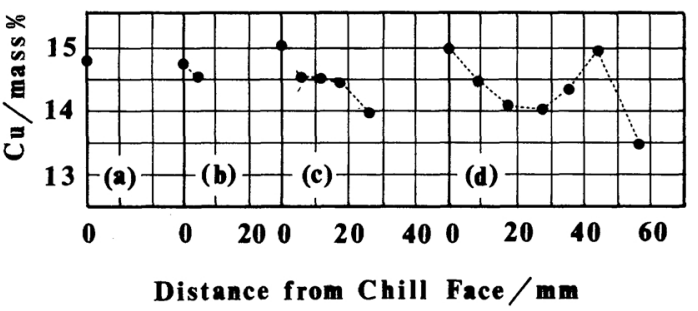

Fig. 14 Variation of $\mathrm{Cu}$ concentration along the length of $\mathrm{Al}-14 \% \mathrm{Cu}$ alloy ingot decanted at the specified times during the unidirectional solidification from the molten surface; (a) $10 \mathrm{~s}$, (b) $25 \mathrm{~s}$, (c) $60 \mathrm{~s}$, (d) $120 \mathrm{~s}$ after start of the water cooling at $933 \mathrm{~K}$, respectively.

there was no recognisable tendency for the copper concentration near the cooling end to increase with time.

Several studies ${ }^{(6)-(9)}$ using the decantation 
method have already been carried out to examine the concentration of solute in the surface layer of an ingot. Fricke, Jr. ${ }^{(6)}$ reported that the solute-rich layer near the surface was related to columnar-equiaxed transition. He explained that when constitutional undercooling occurred in the liquid ahead of the columnar dendrites, solute-rich melt in that region flowed back into the gaps of dendrites, and that the solute concentration of the surface layer was enhanced. In contrast to that report, Edwards and Spit$t^{(8)}$ showed that the earlier the decantation was carried out after the start of solidification, the higher the copper concentration near the cooling end. Nakano et al. ${ }^{(9)}$ explained that the solute-rich surface layer was already formed at the beginning of solidification and the back flow of interdendritic liquid also occurred.

In the present study, in addition to decantation during water cooling from the bottom, decantation during unidirectional solidification from the molten surface was also carried out. As a result, it was found that the copper concentration of the cooled molten surface was higher than the mean composition at the beginning of solidification, as with the case in which it was cooled from the bottom. With unidirectional solidification from the bottom, the influence of gravity segregation must also be taken into account, since the density of copper is greater than that of the bulk liquid, but as the concentration of copper also occurs at the cooled end when cooled from the molten metal surface, it is considered that inverse segregation is not necessarily affected by gravity segregation.

Based on the results of use of the decantation technique in the past and the results of this study, it is presumed that the mechanism for the increase of copper concentration at the cooling end in unidirectional solidification is as follows: The melt near the cooling end directly affected by the water cooling is quickly cooled, and crystals nucleated on the mold wall grow along the cooled surface, as shown in Fig. 15 (a). When adjecent crystals come into contact with each other, they form a stable solid shell, as shown in Fig. 15(b). Solute-rich melt rejected by the growth of crystals at this time cannot move into the cooling end and is, there-

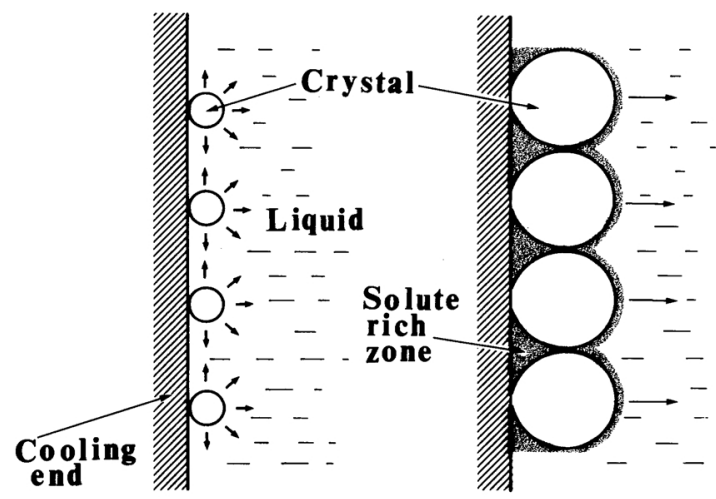

(a)

(b)

Fig. 15 Schematic representations of the solidification behavior on the cooling end; (a) nucleation and growth of crystals on the cooling end, (b) formation of the stable solid shell and trap of the solute rich melt among crystals.

fore, trapped at the roots of crystals.

On the other hand, it was found that copper concentration decreased at the place where solidification was completed to a degree almost equal to the increase at the cooling end. Perhaps this was because the quantity of copper trapped at the cooling end reduced the amount at the place where solidification was completed.

Kaempffer and Weinberg ${ }^{(7)}$ carried out unidirectional solidification from the mold bottom with tracers added to a $\mathrm{Cu}-8 \% \mathrm{Ag}$ alloy melt. They also carried out experiments by removing the chill plate at the bottom at various stages during the process of solidification. They explained that, when heat extraction from the bottom was stopped during unidirectional solidification, solute-rich melt descended through gaps among dendrites, remelting a part of the dendrites, and reached the bottom of the ingot, so that exudation occurred. Such a phenomenon may be expected to occur in a case where the solid shell formed in contact with the mold is separated from the mold wall when the shell thickness is very thin and heat transfer through the mold wall is greatly reduced, for example, in the continuous casting of aluminum alloys. However, in the present study, as the heat is extracted continuously from the cooling end by unidirectional cooling, the temperature near the cooling end quickly drops 
below the solidus temperature, so that the back flow of solute-rich melt is assumed to be unlikely to occur after the solid shell has grown sufficiently although other papers have reported that the back flow did occur even when a solid shell has formed.

In addition, when decantation was carried out after $60 \mathrm{~s}$ from the start of water cooling, as shown in Figs. 13 and 14, it was found that the copper concentration in the region near the solid-liquid interface of the ingot differed greatly from the mean composition. It is assumed that this phenomenon occurred because the copper-rich melt among the dendrites was moved towards the solid-liquid interface by the shock of decantation. It is considered that the copper-rich melt is present among dendrites, because the length of a solid-liquid zone increases as the rate of solidification decreases in regions sufficiently away from the cooling end.

\section{Inverse segregation in ingots with equiaxed structure}

The ingot of $\mathrm{Al}-14 \% \mathrm{Cu}$ alloy horizontally unidirectionally solidified by the start of water cooling at $933 \mathrm{~K}$ formed an entirely equiaxed structure, and that which was solidified by the start of water cooling at $1033 \mathrm{~K}$ consisted of equiaxed and columnar crystals. The distribution of copper concentration in these ingots all showed large variations, and clear inverse segregation was not found. The authors ${ }^{(16)}$ have found the crystal separation phenomenon in the solidification process of some tin alloys by direct observation. Then Gullman and Johansson $^{(17)}$ also observed the phenomenon of crystal separation in many copper alloys. If the process of solidification of $\mathrm{Al}-\mathrm{Cu}$ alloys is assumed to be based on the above results and suppositions, primary $\alpha \mathrm{Al}$ crystals, which were formed at the cooling end and separated from there were, moved with the flow of molten metal, and then solidification took place. However, the distribution of copper concentration in these ingots did not show such a clear tendency of inverse segregation, as was observed in the ingot with only a columnar structure. The reason is thought to be as follows: Primary crystals after being formed and separated were remelted or moved by the convection of molten metal, or the crystal multiplication occurred during solidification, so that equiaxed crystals did not necessarily gather uniformly or regularly.

On the other hand, in the $\mathrm{Al}-14 \% \mathrm{Cu}$ alloy ingot, which was unidirectionally solidified from the molten surface in a graphite mold, equiaxed crystals were present at the bottom. Copper concentration in these ingots was higher near the cooled molten surface, and showed far lower values in the equiaxed zone than at the end where solidification was completed in ingots consisting of only columnar crystals.

The origin of these equiaxed crystals are also assumed to be similar to those found in Al$14 \% \mathrm{Cu}$ alloy ingots solidified horizontally, i.e. among crystals, which were separated from the cooling end and moved to the high temperature part of the molten metal before the growth of columnar crystals, equiaxed crystals which escaped from being remelted after separation could accumulate at the bottom. If these equiaxed crystals had been formed by constitutional undercooling or the remelting of dendrite arms in the process of solidification, the large drop in copper concentration at that place would have hardly been possible.

In contrast to the above case, when cooling the molten surface under the same conditions using a stainless steel mold, no equiaxed crystals appeared in the ingots. The reason for this is assumed to be as follows: The thermal diffusivity of stainless steel, (one of its physical properties which refers to heat transfer through the mold wall) is about 0.04 times as large as that of graphite ${ }^{(20)}$. The amount of heat transfer through the stainless steel mold wall in the unidirectional solidification is small, so that it provides a good heat insulation effect. Accordingly, even if equiaxed crystals are formed, separated and moved into the molten metal, they will be remelted and a structure of columnar crystals alone will be left.

\section{Conclusions}

In order to obtain the basic data of the formation mechanism of inverse segregation which occurs in $\mathrm{Al}-\mathrm{Cu}$ alloy ingots, the horizontal and 
vertical unidirectional solidifications of Al$4 \% \mathrm{Cu}$ and $\mathrm{Al}-14 \% \mathrm{Cu}$ alloys were carried out, and the relationships between the macrostructures and distribution of solute copper in the ingots were examined. The results were as follows:

(1) In ingots made by the decantation technique, copper concentration already increases near the cooling end at the beginning of solidification.

(2) In an ingot consisting only of columnar crystals, copper concentration is high at the cooling end and low at the end where solidification is completed, regardless of the direction of solidification.

(3) With the water cooling of molten $\mathrm{Al}-$ $14 \% \mathrm{Cu}$ alloy at its surface in a graphite mold, columnar crystals grow downwards from the top surface, and equiaxed crystals are present at the lower part of the ingot. Copper concentration becomes higher at the cooling end and becomes very low in the equiaxed zone.

(4) The horizontally unidirectionally solidified ingots of $\mathrm{Al}-14 \% \mathrm{Cu}$ alloy exhibit a structure consisting entirely of equiaxed crystals or the one in which columnar crystals and equiaxed crystals coexist. Clear macrosegregation is not found.

\section{REFERENCES}

(1) K. Obinata: J. Japan Inst. Metals, 4 (1940), 391 (in Japanese).

(2) Y. Nakatani: Keikinzoku, 20 (1970), 199.

(3) G. Massing: Z. Metallk., 14 (1922), 204.

(4) S. Muromachi: J. Japan Inst. Metals, 18 (1964), 101 (in Japanese).

(5) G. Jehmlich: Metall, 1 (1959), 213.

(6) W. G. Fricke, Jr.: Trans. Met. Soc. AIME, 245 (1969), 1126.

(7) F. Kaempffer and F. Weinberg: Met. Trans., 2 (1971), 2477.

(8) K. P. Edwards and J. A. Spittle: Met. Trans., 3 (1972), 1004

(9) K. Nakano, K. Suzuki and S. Ohya: Imono, 45 (1974), 954.

(10) J. S. Kirkaldy and W. V. Youdelis: Trans. Met. Soc. AIME, 212 (1958), 833.

(11) J. R. Cahoon and W. V. Youdelis: Trans. Met. Soc. AIME, 230 (1964), 1734.

(12) M. C. Flemings and G. E. Nereo: Trans. Met. Soc. AIME, 239 (1967), 1449.

(13) H. Vesskuhler: Z. Metallk., 56 (1965), 719.

(14) T. Tanabe and H. Syōji: Imono, 12 (1940), 383.

(15) I. Igarashi and S. Hiraiwa: Imono, 13 (1941), 497.

(16) T. Motegi and A. Ohno: J. Japan Inst. Metals, 45 (1981), 1215 (in Japanese).

(17) L. O. Gullman and L. Johansson: Solidification and Casting of Metals, The Metals Society, (1979), p. 198.

(18) A. Ohno, T. Motegi and H. Sōda: J. Japan Inst. Metals, 35 (1971), 11 (in Japanese).

(19) G. S. Cole and G. F. Bolling: Trans. Met. Soc. AIME, 235 (1965), 1568.

(20) Nippon Kikai Gakkai: Dennetsu Kogaku Shiryō, (1975), 294. 